Document downloaded from:

http://hdl.handle.net/10251/109833

This paper must be cited as:

Ruiz Fernández, LÁ.; Recio Recio, JA.; Crespo-Peremarch, P.; Sapena, M. (2018). An object-based approach for mapping forest structural types based on low-density LiDAR and multispectral imagery. Geocarto International. 33(5):443-457.

doi:10.1080/10106049.2016.1265595

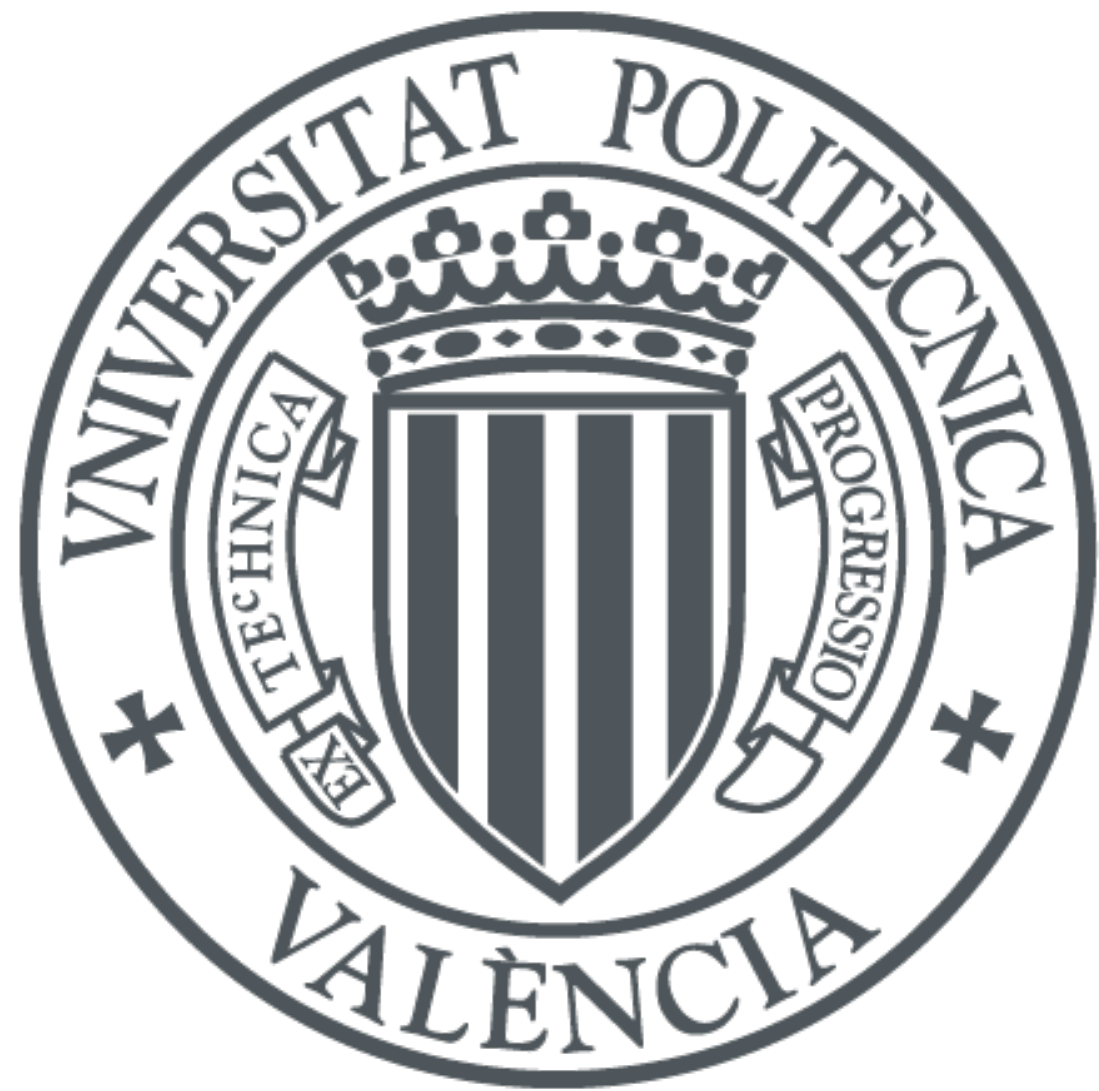

The final publication is available at

https://doi.org/10.1080/10106049.2016.1265595

Copyright Taylor \& Francis

Additional Information 


\section{An object-based approach for mapping forest structural types based on low density LiDAR and multispectral imagery}

\section{Luis Ángel Ruiz, Jorge Abel Recio, Pablo Crespo-Peremarch \& Marta Sapena}

To cite this article: Luis Ángel Ruiz, Jorge Abel Recio, Pablo Crespo-Peremarch \& Marta Sapena (2016): An object-based approach for mapping forest structural types based on low density LiDAR and multispectral imagery, Geocarto International, DOI: 10.1080/10106049.2016.1265595

To link to this article: http://dx.doi.org/10.1080/10106049.2016.1265595

Accepted author version posted online: 28

Nov 2016.

Submit your article to this journal

à

View related articles 주

View Crossmark data $₫$ 
Publisher: Taylor \& Francis

Journal: Geocarto International

DOI: http://dx.doi.org/10.1080/10106049.2016.1265595

\section{An object-based approach for mapping forest structural types based on low density LiDAR and multispectral imagery}

Luis Ángel Ruiz, Jorge Abel Recio, Pablo Crespo-Peremarch, Marta Sapena

Geo-Environmental Cartography and Remote Sensing Group (CGAT), Universitat Politècnica de València, Valencia, Spain

Corresponding author:

Luis Ángel Ruiz (laruiz@cgf.upy.es)

Depto. Ingeniería Cartográfica, Geodesia y Fotogrametría, Universitat Politècnica de València, Camî́ de Vera s/n 46022 - Valencia, Spain.

\section{Acknowledgements}

This work was supported by the Spanish Ministerio de Economía y Competitividad and FEDER under Grant CGL2013-46387-C2-1-R; and Fondo de Garantía Juvenil under contract PEJ-2014-A-45358. The authors also thank the Spanish Instituto Geográfico Nacional (IGN) for making available the LiDAR data used. 


\title{
An object-based approach for mapping forest structural types based on low density LiDAR and multispectral imagery
}

\author{
Mapping forest structure variables provides important information for estimation \\ of forest biomass, carbon stocks, pasture suitability or for wildfire risk prevention \\ and control. The optimization of the prediction models of these variables requires \\ an adequate stratification of the forest landscape in order to create specific \\ models for each structural type or strata. This paper aims to propose and validate \\ the use of an object-oriented classification methodology based on low density \\ LiDAR data $\left(0.5 \mathrm{~m}^{-2}\right)$ available at national level, WorldView-2 and Sentinel-2 \\ multispectral imagery to categorize Mediterranean forests in generic structural \\ types. After preprocessing the data sets, the area was segmented using a \\ multiresolution algorithm, features describing 3D yertical structure were \\ extracted from LiDAR data, and spectral and texture features from satellite \\ images. Objects were classified after feature selection in the following structural \\ classes: grasslands, shrubs, forest (without shrubs), mixed forest (trees and \\ shrubs) and dense young forest. Four classification algorithms (C4.5 decision \\ trees, random forest, k-nearest neighbor and support vector machine) were \\ evaluated using cross-validation techniques. The results show that the integration \\ of low density LiDAR and multispectral imagery provide a set of complementary \\ features that improve the results ( $90.75 \%$ overall accuracy), and the object- \\ oriented classification techniques are efficient for stratification of Mediterranean \\ forest areas in structural and fuel related categories. Further work will be focused \\ on the creation and validation of a different prediction model adapted to the \\ various strata.
}

Keywords: fuel strata, object-based classification, LiDAR, WorldView-2, Sentinel-2

\section{Introduction}

The concept of forest structure refers to the three-dimensional distribution of all the elements that configure a forest stand, including species type, size, ages, variety, heights strata, and others. Their characterization is usually performed by direct in-field measurements or indirect estimations from remote sensing data, such as multispectral, 
hyper-spectral, radar images or LiDAR data. A particular group of forest structural variables are those used to describe and quantify the fuel potential of the stands. The estimation and mapping of fuel variables, such as canopy base height, canopy fuel load or canopy bulk density, are important because they constitute some of the inputs needed to predict and model the fire behaviour, in order to reduce the risk and the effect of wildfires. During the last decade, LiDAR-based fuel variables prediction models have been developed in many areas of the world and under different ecological conditions using discrete (Riaño et al. 2003, 2004; Andersen et al. 2005; Popescu \& Zhao 2008; Erdody \& Moskal 2010; González-Olabarría et al. 2012) and full-waveform data (Hermosilla et al. 2014; Crespo-Peremarch et al. 2016). In order to obtain accurate estimations of structural variables, it is more efficient to divide the working area in strata or patches attending to their specific structural type, and then to develop a particular model for each of the classified strata (Latifi et al. 2012). Information on forest type and forest structure is also critical to land managers for accurate forest inventory and ecological monitoring (Kennaway et al. 2008), and to improve estimations of forest biomass, carbon stocks, etc. Different data sets and methods have been used for mapping forest structure. Thus, Vohland et al. (2007) identified eight forest classes with an overall accuracy of $87.5 \%$ using a supervised parametric classification based on a Landsat-5 TM scene, in order to predict more accurately the stem number per hectare for Norway spruce. Zhang and Franklin (2002) used texture features from high-resolution multispectral imagery to improve forest structure classification, considering that textures would be less sensitive to random variations in spectral response and more related to structural features, such as crown size and shape, obtaining $83 \%$ classification accuracy for nine classes. Kennaway et al. (2008) used pan-sharpened Landsat ETM+ images and decision trees to classify and map land cover 
and forest type for the Virgin Islands, illustrating a low cost approach. However, they found difficulty in distinguishing very small forest patches, small clearings or manmade structures in forest. More recently, Mishra \& Crews (2014) used Landsat TM imagery and topographic variables to map structural vegetation types in a dry savanna. Combining features related to structure and intensity from LiDAR data, Orka et al. (2009) reached an overall classification accuracy of $88 \%$ to discriminate between coniferous and deciduous tree species. Sullivan et al. (2009) recommended stand delineation as an important step in the process of establishing a forest inyentory, also providing the spatial framework for many forest management decisions. These authors investigated the use of LiDAR data as a potential tool for delineation of forest structure to create stand maps in six stand structural classes using object-oriented supervised classification, and Dalponte et al. (2008) analyzed the joint effect of hyperspectral and LiDAR data for the classification of complex forest areas, finding that the elevation channel of the first LiDAR return was very effective for the separation of species with similar spectral signatures but different mean heights. Martín Alcón et al. (2015) combined LiDAR and multispectral imagery to assess post-fire regeneration types.

Other approaches were developed to characterize 3-D layers within forests patches for fuel mapping using LiDAR (Ferraz et al. 2012), or combining it with multispectral (García et al. 2011), hyperspectral images (Varga \& Asner 2008) or aerial ortho-images (Rosa \& Stow 2013). This stratification can be obtained using image classification techniques (Riaño et al. 2007; Mutlu et al. 2008; Parent et al. 2015), which provide a more efficient approach than using traditional photointerpretation (Arroyo et al. 2008). Due to the discontinuous character of many forested areas, especially those located in steep mountain zones, object-oriented classification techniques seem to be appropriate 
to achieve these spatially complex classifications. Object-based classifications have been successfully used for this purpose in Arroyo et al. (2006) and García et al. (2011). Chirici et al. (2013) used multispectral IRS LISS-III images and LiDAR data to classify forest fuel types in two areas of Sicily (Italy) using regression trees. Blanchard et al. (2011) used LiDAR and object-based image analysis (OBIA) for classification and quantification of downed logs on the forest floor, obtaining $73 \%$ of classification accuracy. Dupuy et al. (2013) used similar data to discriminate six vegetation classes based on canopy height and horizontal heterogeneity, and Hellesen \& Matikainen (2013) for mapping small shrubs and trees. In general, the results reported are obtained in specific ecological areas and structural types. As a result of some tests performed by Kennaway et al. (2008) for mapping forest structural attributes using coarse-resolution discrete LiDAR data, they concluded that further work is needed in stratification of forest types. It is still needed to evaluate the performance of different classifiers, as well as to compare a variety of combinations of very low-density LiDAR data and new multispectral imagery.

The objectives of this work are to compare and evaluate a stratification method based on low density country-wide LiDAR data and multispectral satellite imagery that allow us for the classification of basic generic types present in our study area, typically Mediterranean, and to assess the use of the newly available Sentinel-2 images and their joint use with LiDAR, as compared to other very high resolution images, such as the WorldView-2 multispectral images. 


\section{Material and methods}

\section{Study area and field data}

The Natural Park of Sierra de Espadán is located in the central Mediterranean region of Spain, in the foothills of the Iberian System, with a topography characterized by very steep slopes, ranging from an altitude close to sea level to $1100 \mathrm{~m}$. Due to the orientation of the mountain range, there is slightly more accumulation of rainfall than what it would be expected for this location. The study area (Figure 1) has an extension of about 15,400 ha, approximately half the extension of the Natural Park. The dominant forest species are Pinus halepensis, Pinus pinaster and Quercus suber, other species are Castanea sativa, Acer sp. or Arbutus unedo. There is also an important presence of shrubs and high herbaceous species (Quercus faginea, Ilex aquifolium, Genista scorpius, Erica sp, Juniperus phoenicea, among others) appearing in patches or as understory forest vegetation layers.

[Figure 1 here]

A field data campaign was done in September 2015, as part of a complete forest inventory data collection, where standard forest inventory measurements $(\mathrm{DBH}$, tree heights, and number of trees) were registered in 80 circular plots (15 m radius), as well as descriptive information concerning types of vegetation and strata. The area suffered localized recurrent wildfires from different severity degrees and distributed in patches of a variety of sizes, mainly during the decade of 1990. During the last years, there has been a lack of forest maintenance works, which facilitates the creation of patches with trees together with a dense bushy and herbaceous vegetation layer. From forest fuel and fire behaviour perspectives, and aiming to eventually facilitate the generation of fuel 
quantitative prediction models, four generic vegetation strata were differentiated (Figure 2).

(1) Forest: composed by $P$. pinaster and $P$. halepensis, often combined with Quercus suber, with no presence of shrub or understory vegetation layer (Figure 2a). (2) Mixed forest: this is a combination of pine trees and shrub or high herbaceous vegetation, usually conforming a dense understory layer (Figure 2b). (3) Shrub: dense shrub species, sometimes with the presence of isolated trees (Figure 2c). (4) Young forest: very dense concentration of young $P$. halepensis trees, with densities ranging from 20,000 to 40,000 trees/ha, distributed in patches as a result of spontaneous regeneration after wildfires (Figure 2d). A fifth strata or class, Grassland, with very low occurrence in the study area, was defined to complete the structural vegetation types for classification.

[Figure 2 here]

\section{LiDAR data}

LiDAR data were acquired by a RIEGL LMS-Q680 laser scanner device during the summer of 2009 as part of the Spanish National Aerial Orthophotography Programme (PNOA), with an average density of 0.5 pulses $\mathrm{m}^{-2}$ and distributed by the National Mapping Agency (IGN). The point cloud was first filtered to eliminate outliers, then the points belonging to the terrain were preserved using FUSION 3.5 software (McGaughey 2015), and improved using a broad ( $5 \mathrm{~m} / \mathrm{pixel}$ ) digital terrain model (DTM) provided by the IGN as ancillary data, so that the height value of those points from the filtered cloud whose height differed in more than $1 \mathrm{~m}$ from the ancillary DTM, were reassigned with the height of this broader DTM. This process allowed us to clean the point cloud from 
misclassified terrain points, in order to create the new $2 \mathrm{~m}$ DTM. The digital surface model (DSM) or canopy height model (CHM) was obtained by selecting the maxima height in a grid of $2 \mathrm{~m}$. Finally, a normalized digital surface model (nDSM) of the same resolution was obtained by subtracting the DTM from the DSM, and a 3x3 median filter was applied to avoid pixels with zero value caused by occasional lack of points in the final $2 \times 2 \mathrm{~m}$ cells, due to the very low density of LiDAR data.

\section{Image data}

A WorldView-2 eight bands multispectral image ( $2 \mathrm{~m} /$ pixel spatial resolution) from November 2013 was orthorectified using the RPC parameters in the metadata, control points and the DTM model from the PNOA programme. A Sentinel-2 image acquired in December $3^{\text {rd }}, 2015$ was downloaded from the Copernicus Sentinels Scientific Data Hub repository (https://scihub.copernicus.eu), and georeferenced with the SNAP Sentinel toolbox (v.3.0) using the image metadata file, according to the three different spatial resolutions of the thirteen spectral bands available $(10,20$ and $60 \mathrm{~m} /$ pixel spatial resolution). Sentinel-2 images were clipped to the same size as the WorldView-2 image, representing the complete study area.

Figure 3 shows a flowchart of the object-oriented methodology followed, beginning with the data pre-processing, object definition, feature extraction and generation of classification models.

[Figure 3 here] 


\section{Segmentation and Feature Extraction}

Segmentation is a previous step to classification in object-based image analysis, consisting on the definition of objects, or groups of pixels, based on their spatial homogeneity according to one or several properties. Considering that segmentation algorithms become increasingly instable with growing input space dimension (Roth \& Lange 2004), we used only the nDSM obtained from LiDAR and the normalized difference vegetation index (NDVI) from the WorldView-2 image as input data for segmentation, therefore the objects generated were homogeneous in terms of the presence and density of vegetation, and the height of the elements within the objects.

The multiresolution algorithm implemented in eCognition software (Baatz \& Shäpe 2000) was applied, using a scale factor of 10, a weight for the objects shape 0.1 and for the bands (NDVI+nDSM) 0.9. Additionally, two vector layers extracted from the official Topographic Map of the Comunitat Valenciana, BCV05 (1:5000), corresponding to roads and buildings, were used as input masks in order to exclude these elements from the classification process. Figure 4 shows a detail of the final segments generated.

Feature extraction was performed using two freely available software programmes: FUSION 3.5 (McGaughey 2015) and FETEX 2.0 (Ruiz et al. 2011). The former was used to extract a set of statistical features computed from the normalized LiDAR point cloud, using point elevations and intensity. FETEX 2.0 is a feature extraction software tool that accepts images and segment limits as inputs and calculate a set of spectral, texture, structure and shape features of every object. In our case, spectral features (mean and standard deviation of intensity values) were computed from all bands of WorldView-2 and Sentinel-2 images. Texture features were computed from the red band of satellite images, including those derived from the grey level cooccurrence matrix and the features extracted from the semivariogram of the intensity 
values of pixels within each object, as described by Balaguer et al. (2010). Shape features based on object area and perimeter (compactness, fractal dimension and shape index) were also extracted. The complete set of features extracted from the different data sources is summarized in Table 1.

[Table 1 here]

Based on the qualitative information collected in the field campaign, and by photointerpretation of the WorldView-2 image and the LiDAR data, a total of 482 objects were selected as training samples in a first binary classification step to discriminate between agricultural (128 objects) and non-agricultural (354 objects). Then, the 354 non-agricultural objects were used as samples for a second and more specific classification into generic structural strata. There are two main alternatives for the selection of samples, proportional to area or equal allocation. In former studies, Colditz (2015) recommended area proportional training sample allocation of each class for classification trees. Jin et al. (2014) also suggest proportionally allocated sampling designs to increase overall accuracy and to reduce RMSE in urban areas, but always considering that the choice of an appropriate sampling design for training data selection is generally an application-specific decision. In our case, the number of samples per class was defined according to their approximate proportion in the study area. In consequence, samples were distributed as follows: 40 samples of class forest, 10 of grassland, 214 of mixed-forest, 56 of shrub, and 34 of young forest. Figure 4 shows some examples of samples used for the five classes.

[Figure 4 here] 
The GreedyStepwise algorithm from WEKA 3 (Hall et al. 2009) was used for feature selection. This method performs a forward search through the space of attribute subsets, starting with no attributes, and stops when the addition of any remaining attributes results in a decrease in the evaluation. Additionally, we set a more restrictive threshold of $0.5 \%$ of increase rate in the overall accuracy per step for the stepwise process to stop, and a maximum of six attributes.

\section{Classification of generic structural types}

Classification of Agricultural and Non-agricultural areas

Subsistence mountain agriculture used to be a traditional land use in the study area, with the existence of small orchards arranged in terraces to reduce the effect of the slope. Even if nowadays these areas have been sharply reduced, some of them still remain close to the valleys or interleaved with the forest. Since our purpose was focused on the classification of fuel types, and the availability of LiDAR and spectral data made feasible the accurate pre-classification of agricultural lands, a previous binary classification was done to mask agricultural from non-agricultural segments. For this purpose, the C4.5 decision tree classification algorithm (Quinlan 1993) was used. Previous to the classification, the feature selection was performed considering all the available features and the classes 'Agricultural' and 'Non-agricultural'.

Once the agricultural areas were masked, two classification tests were performed: First, four classification algorithms were compared using the selected features from all data sets; secondly, the effectiveness of various groups of data sources was evaluated. 
With the features selected from the whole dataset $(\mathrm{S} 2+\mathrm{WV} 2+\mathrm{L})$, four classification methods were compared: C4.5 decision trees, Random Forest (RF), k-nearestneighbours (k-NN), and Support Vector Machine (SVM). All of them were implemented using WEKA 3 software. The C4.5 decision trees algorithm (Quinlan 1993) consists on a set of mutually exclusive conditions organised in a hierarchical structure, created iteratively by dividing the initial sample in subgroups and using a splitting criterion until the dynamically generated subgroups become homogeneous. Random Forests (Breiman 2001) is a method based on the construction of multiple decision trees that are averaged and trained on different parts of the same training set, with the goal of reducing the variance (Hastie et al, 2008). The k-NN classification algorithm computes the distances in the feature space of objects with respect to $\mathrm{k}$ prototypes per class defined from the training samples, assigning each object to the class most common among its $\mathrm{k}$ nearest neighbours. In our tests we used $\mathrm{k}=5$. The Support Vector Machine algorithm is based on finding the hyperplane that gives the largest minimum distance to the training examples. Therefore, the optimal separating hyperplane maximizes the margin of the training data (Cortes \& Vapnik 1995). The classification results of these four methods were expressed in terms of overall accuracy and kappa index for comparison purposes.

\section{Evaluation of data source groups for structural type classification}

Four different classifications in the five structural types described were conducted, using the following groups of features: using only LiDAR features (L); Sentinel-2 and LiDAR (S2+L); WorldView-2 and LiDAR (WV2+L); and all features (S2+WV2+L). Since discrimination of vegetation height layers was needed, the use of only Sentinel-2 
or WorldView-2 was discarded due to the lack of height information. For the four groups of features, the same feature selection process was performed, and the C4.5 decision tree classification algorithm was used in all cases. Results were compared by reporting the overall, producer's and user's accuracies, and the kappa index, all obtained from the respective error matrices. In all cases, these results were expressed considering the number of objects correctly or incorrectly classified, as well as weighted by the area represented by the objects.

As a mechanism to avoid overfitting, a common method is to split the samples in two parts, one for model calibration, and one for evaluating the predictive error. Methods that use this approach include leave-one-out cross-validation, k-fold crossvalidation, as well as repeated splits in training and validation samples (Kuhn \& Johnson 2013). Cross-validation is a widely used evaluation method when a small number of samples are available. After a preliminary test of the number of folds, stratified cross-validation in ten folds was used to evaluate the classification results in all the tests performed.

\section{Results}

The results and discussion of the object-based classification tests are independently organized in the next three sub-sections.

\section{Classification of Agricultural and Non-agricultural areas}

Discrimination between agricultural land use and non-agricultural was efficiently performed by the decision tree using only three variables: height percentiles 95 and 20 , and the contrast derived from the grey level co-occurrence matrix of the WorldView-2 red band. From a sample of 482 objects, a total of 463 were correctly classified, which means a $96.06 \%$ of accuracy (0.9 kappa index). Considering the results after weighting 
by the actual area of each classified segment, the overall accuracy was $96.16 \%(0.92$ kappa index). This shows the ability to mask out the agricultural crops using a simple decision tree based on height features from LiDAR and texture information extracted from high-resolution satellite imagery, without using spectral information. The use of such decision tree as a preliminary step of the classification allows for the reduction of complexity in the classification of forest fuel types.

\section{Comparison of Classification Methods}

After application of the stepwise feature selection algorithm, the final variables used for classification are shown in Table 2. In all cases, elevation percentile 90 from LiDAR data is one of the first features selected. Spectral information, either from the WorldView-2, Sentinel-2 or LiDAR intensity data is also selected, which confirms a complementary effect of spectral and 3D features.

[Table 2 here]

The summary of the results obtained with the four classification methods tested is shown in Table 3. All methods except for SVM perform well, ranging from $86.76 \%$ to $90.75 \%$ of oyerall accuracy. C4.5 decision tree algorithm performs slightly better in terms of the total area correctly classified. However, random forest accuracy is slightly higher when the number of objects correctly classified is considered. Even considering that both methods provide a high overall accuracy, we chose the method of C4.5 decision trees for the classification comparative tests using different groups of data sources. Compared to a recent study about classification of forest development stages in Finland (Valbuena et al. 2016), random forest seems to be a robust classifier for 
different areas and forest conditions, while support vector machine has a more variable performance.

[Table 3 here]

\section{Evaluation of Data Source Groups}

After a preliminary test, we discarded the use of only WV2 or S2 images, due to the very low overall accuracies obtained (below 70\%) when using only spectral information. Classification of forest fuel types produced good overall accuracy results using the other four combinations of data sources tested, obtaining $90.75 \%$ of accuracy in weighted area combining the three data sets $(\mathrm{WV} 2+\mathrm{S} 2+\mathrm{L})$ (Table 4). Therefore, the use of LiDAR, that provides information about the height distribution of the canopy layers, seems to be necessary in order to obtain operative performance. The lowest accuracies were obtained $(82.2 \%-88.2 \%)$ using LiDAR without multispectral information, however the difference is only $3-4 \%$ less than using the combination of all data sets $(\mathrm{WV} 2+\mathrm{S} 2+\mathrm{L})$. In this sense, these results confirm those obtained by García et al. (2011) and by Chirichi et al. (2013), but using a very low density LiDAR data and an object-oriented approach. This approach allowed us for the calculation of metrics from low density LiDAR, since the size of objects is larger than the pixel size and a minimum number of points is ensured for the computation of metrics.

[Table 4 here]

In terms of class-specific accuracies (producer's and user's) the results show that it is necessary to combine LiDAR data with high-resolution multispectral images 
(WV2) in order to discriminate class forest with a minimum of confidence level (Figures 5 and 6).

Using $\mathrm{L}$ or $\mathrm{L}+\mathrm{S} 2$ data sets produced a very low user's accuracy, while the former produced a very low producer's accuracy for this class. As described in subsection 2.1, class forest is composed of Pinus trees sometimes mixed with Quercus suber in different proportions. This irregular composition increases the variability within the class and consequently makes more difficult to characterize the class for classification purposes. Misclassification occurs mainly by confusion with objects from mixed forest class, which is also composed of Pinus trees, but associated with a more or less dense layer of understory shrub. Class mixed forest does not seem to be as sensitive to these errors, due to the higher proportion in the study area, and therefore having a larger number of samples represented in the training/testing set.

[Figure 5 here]

[Figure 6 here]

In our case, the class young trees was properly segmented and correctly classified, which is relevant to obtain accurate fuel or forest structure variable prediction models. Therefore, the object-based approach used facilitates the delineation of patches with specific structural types existing in the landscape. In addition to the combination of multispectral and LiDAR data, future work may explore the use of multitemporal data available from middle-resolution imagery such as Landsat or Sentinel-2, similar to the work reported by Fagan et al. (2015), who examined the potential of combining moderate-resolution hyperspectral imagery with multitemporal, multispectral data 
(Landsat) to accurately classify general forest types, finding that adding multitemporal data significantly improved classification accuracy. The application of this methodology in a larger area with more variety of structural forest types could help to obtain more accurate and complete prediction models for forest structure variables.

Figure 7 shows the final classification result obtained after following the proposed methodology, using the $\mathrm{C} 4.5$ decision tree classifier and a representation of features from the three data sets tested.

[Figure 7 here]

\section{Conclusions}

An object-based classification approach has been presented for classification of generic fuel types of a Mediterranean area in Spain, in order to facilitate structure and fuel variable prediction models based on LiDAR data.

Due to the typical irregular distribution of forest stands in these areas, a preliminary binary elassification in agricultural and non-agricultural land using LiDAR and texture data from images was carried out, resulting in high accuracy and consequently reducing the complexity for a second classification in structural types.

Regarding structural type classification, decision trees (C4.5) and random forest classifiers performed better than SVM and k-NN, allowing for overall accuracies near $90 \%$, which makes these methods highly operative for practical applications.

For discrimination of structural types, the parameters derived from LiDAR data are more relevant than those obtained from multispectral imagery, since they convey information from the vertical structure of the vegetation canopy, which is crucial to distinguish the distribution of different vertical vegetation strata and species that are 
within the objects. Additionally, it is suitable to combine both data sources, particularly when two or more tree species (P. halepensis, $P$. pinaster, $Q$. suber) or tree types (i.e., conifers and broad leaf trees) coexist in the same object. For this purpose, very high resolution images, such as WV2, increase the accuracies with respect to the medium resolution images. Sentinel-2 images would perform better when larger objects are generated after segmentation, or broader scales are considered.

Object-oriented classification techniques combining multispectral imagery and low density LiDAR data resulted to be efficient for stratification of fuel types prior the fuel modelling phase, which opens new possibilities to optimise the structure and fuel variable mapping in Mediterranean areas. Future work in larger areas should be focused on the discrimination of more specific structural classes, such as pine-dominated and oak-dominated forests, in order to obtain separate models that improve the prediction of forest structure and fuel variables. The estimation of the proportions of forest types mix within strata could also be considered for the generation of hybrid prediction models. 


\section{References}

Andersen HE, McGaughey RJ, Reutebuch SE. 2005. Estimating Forest Canopy Fuel Parameters Using LIDAR Data. Remote Sens. Environ. 94:441-449.

Arroyo LA, Healey SP, Cohen WB, Cocero D, Manzanera JA. 2006. Using ObjectOriented Classification and High-Resolution Imagery to Map Fuel Types in a Mediterranean Region. J. Geophys. Res. Biogeosciences. 111: 2156-2202. Arroyo LA, Pascual C, Manzanera JA. 2008. Fire Models and Methods to Map Fuel Types: The Role of Remote Sensing. For. Ecol. Manage. 256:1239-1252.

Baatz M, Schäpe A. 2000. Multiresolution Segmentation: An Optimization Approach for High Quality Multi-Scale Image Segmentation. In: Strobl J, et al. (eds.): Angewandte Geographische Informationsverarbeitung XII. Wichmann, Heidelberg; p. 12-23.

Balaguer A, Ruiz LA, Hermosilla T, Recio JA. 2010. Definition of a comprehensive set of texture semivariogram features and their evaluation for object-oriented image classification. Comput. Geosci. 36:231-240.

Blanchard SD, Jakubowski MK, Kelly M. 2011. Object-Based Image Analysis of Downed Logs in Disturbed Forested Landscapes Using Lidar. Remote Sens. $3: 2420-2439$.

Breiman L. 2001. Random Forests. Mach. Learn. 45:5-32.

Chirici G, Scotti R, Montaghi A, Barbati A, Cartisano R, Lopez G, Marchetti M, McRoberts RE, Olsson H, Corona P. 2013. Stochastic Gradient Boosting Classification Trees for Forest Fuel Types Mapping through Airborne Laser Scanning and IRS LISS-III Imagery. Int. J. Appl. Earth Obs. 25:87-97.

Colditz RR. 2015. An Evaluation of Different Training Sample Allocation Schemes for Discrete and Continuous Land Cover Classification Using Decision Tree-Based Algorithms. Remote Sens. 7: 9655-9681.

Cortes C, Vapnik V. 1995. Support-vector networks. Mach. Learn. 20: 273-297. Crespo-Peremarch P, Ruiz LA, Balaguer-Beser A. 2016. A comparative study of regression methods to predict forest structure and canopy fuel variables from LiDAR full-waveform data. Rev. Teledetec. 45:27-40.

Dalponte M, Bruzzone L, Gianelle D. 2008. Fusion of Hyperspectral and LIDAR Remote Sensing Data for Classification of Complex Forest Areas. IEEE Trans. Geosc. Remote Sens. 46:1416-1427. 
Dupuy S, Lainé G, Tassin J, Sarrailh JM. 2013. Characterization of the horizontal structure of the tropical forest canopy using object-based LiDAR and multispectral image analysis. Int. J. of Appl. Earth Obs. 25:76-86.

Erdody TL, Moskal LM. 2010. Fusion of LiDAR and Imagery for Estimating Forest Canopy Fuels. Remote Sens. Environ. 114:725-737.

Fagan ME, DeFries RS, Sesnie SE, Arroyo-Mora JP, Soto C, Singh A, Townsend PA, Chazdon RL. 2015. Mapping Species Composition of Forests and Tree Plantations in Northeastern Costa Rica with an Integration of Hyperspectral and Multitemporal Landsat Imagery. Remote Sens. 7:5660-5696.

Ferraz A, Bretar F, Jacquemoud, S, Gonçalves G, Pereira L, Tomé M, Soares P. 2012. 3-D Mapping of a Multi-Layered Mediterranean Forest Using ALS Data. Remote Sens. Environ. 121:210-223.

García, M, Riaño D, Chuvieco E, Salas J, Danson FM. 2011. Multispectral and LiDAR Data Fusion for Fuel Type Mapping Using Support Vector Machine and Decision Rules. Remote Sens. Environ. 115:1369-1379.

González-Olabarría JR, Rodríguez F, Fernández-Landa A, Mola-Yudego B. 2012. Mapping fire risk in the Model Forest of Urbión (Spain) based on airborne LiDAR measurements. For. Ecol. Manage. 282:149-156.

Hall M, Frank E, Holmes G, Pfahringer B, Reutemann P, Witten IH. 2009. The WEKA Data Mining Software: An Update. ACM SIGKDD Explorations. 11:10-18.

Hastie T, Tibshirani R, Friedman J. 2008. The Elements of Statistical Learning (2nd ed.). Springer.

Hellesen T, Matikainen L. 2013. An object-based approach for mapping shrub and tree cover on grassland habitats by use of LiDAR and CIR orthoimages. Remote Sens. 5:558-583.

Hermosilla T, Ruiz LA, Kazakova AN, Coops NC, Moskal LM. 2014. Estimation of Forest Structure and Canopy Fuel Parameters from Small-Footprint FullWaveform LiDAR Data. Int. J. Wildl. Fire. 23: 224-233.

Jin H, Stehman SV, Mountrakis G. 2014. Assessing the impact of training simple selection on accuracy of an urban classification: a case study in Denver, Colorado. Int. J. Remote Sens. 35:2067-2081.

Kennaway TA, Helmer EH, Lefsky MA, Brandeis TA, Sherrill KR. 2008. Mapping Land Cover and Estimating Forest Structure Using Satellite Imagery and Coarse Resolution Lidar in the Virgin Islands. J. Appl. Remote Sens. 2(1):23551. 
Kuhn M, Johnson K. 2013. Applied predictive modeling. New York: Springer Science + Business Media

Latifi H, Fassnacht F, Koch B. 2012. Forest Structure Modeling with Combined Airborne Hyperspectral and LiDAR Data. Remote Sens. Environ. 121:10-25.

Martín-Alcón S, Coll L, De Cáceres M, Guitart L, Cabré M, Just A, González-Olabarría JR. 2015. Combining aerial LiDAR and multispectral imagery to assess postfire regeneration types in a Mediterranean forest. Can. J. For. Res. 45:856-866.

McGaughey RJ. 2015. FUSION/LDV: Software for LIDAR data analysis and visualization. USDA Forest Service, Pacific Northwest Research Station.

Mishra NB, Crews KA. 2014. Mapping vegetation morphology types in a dry savanna ecosystem: Integrating hierarchical object-based image analysis with random forest. Int. J. Remote Sens. 35:1175-1198.

Mutlu M, Popescu SC, Stripling C, Spencer T. 2008. Mapping Surface Fuel Models Using Lidar and Multispectral Data Fusion for Fire Behavior. Remote Sens. Environ. 112:274-285.

Ørka HO, Næsset E, Bollandsås OM. 2009. Classifying Species of Individual Trees by Intensity and Structure Features Derived from Airborne Laser Scanner Data. Remote Sens. Environ. 113:1163-1174.

Parent JR, Volin J C, Civco DL, 2015. A fully-automated approach to land cover mapping with airborne LiDAR and high resolution multispectral imagery in a forested suburban landscape. ISPRS J. of Photogram. Remote Sens. 104:18-29.

Popescu SC, Zhao K. 2008. A Voxel-Based Lidar Method for Estimating Crown Base Height for Deciduous and Pine Trees. Remote Sens. Environ. 112:767-781.

Quinlan JR. 1993. C4.5. Programs for machine learning. Morgan Kaufmann: San Mateo.

Riaño D, Meier E, Allgöwer B, Chuvieco E, Ustin SL. 2003. Modeling Airborne Laser Scanning Data for the Spatial Generation of Critical Forest Parameters in Fire Behavior Modeling. Remote Sens. Environ. 86:177-186.

Riaño D, Chuvieco E, Condés S, González-Matesanz J, Ustin SL. 2004. Generation of Crown Bulk Density for Pinus Sylvestris L. from Lidar. Remote Sens. Environ. 92:345-352.

Riaño D, Chuvieco E, Ustin SL, Salas J, Rodríguez-Pérez JR, Ribeiro LM, Viegas DX, Moreno JM, Fernández H. 2007. Estimation of Shrub Height for Fuel-Type 
Mapping Combining Airborne LiDAR and Simultaneous Color Infrared Ortho Imaging. Int. J. Wildl. Fire. 16:341-348.

Rosa MF, Stow DA. 2013. Mapping fuels at the wildland-urban interface using colour ortho-images and LiDAR data. Geocarto Int. 29:570-588.

Roth V, Lange T. 2004. Pattern Recognition: Adaptive feature selection in image segmentation. Berlin, Germany: Springer-Verlag; p. 9-17.

Ruiz LA, Recio JA, Fernández-Sarría A, Hermosilla T. 2011. A feature extraction software tool for agricultural object-based image analysis. Comput. Electron. Agric. 76:284-296.

Sullivan AA, McGaughey RJ, Andersen HE, Schiess P. 2009. Object-Oriented Classification of Forest Structure from Light Detection and Ranging Data for Stand Mapping. West. J. Appl. For. 24:198-204.

Valbuena R, Maltamo M, Packalen P. 2016. Classification of forest development stages from national low-density LiDAR datasets: a comparison of machine learning methods. Rev. Teledetec. 45:15-25.

Varga TA, Asner GP. 2008. Hyperspectral and LiDAR Remote Sensing of Fire Fuels in Hawaii Volcanoes National Park. Ecol. Appl. 18:613-623.

Vohland M, Stoffels J, Hau C, Schüler G. 2007. Remote Sensing Techniques for Forest Parameter Assessment: Multispectral Classification and Linear Spectral Mixture Analysis. Silva Fennica 41:441-456.

Zhang C, Franklin SE. 2002. Forest Structure Classification Using Airborne Multispectral Image Texture and Kriging Analysis. IEEE Int. Geosc. Remote Sens. Symposium 4: 2522-2524. 
Table 1. Complete set of features extracted from the objects, organized attending to the different data sources and typologies.

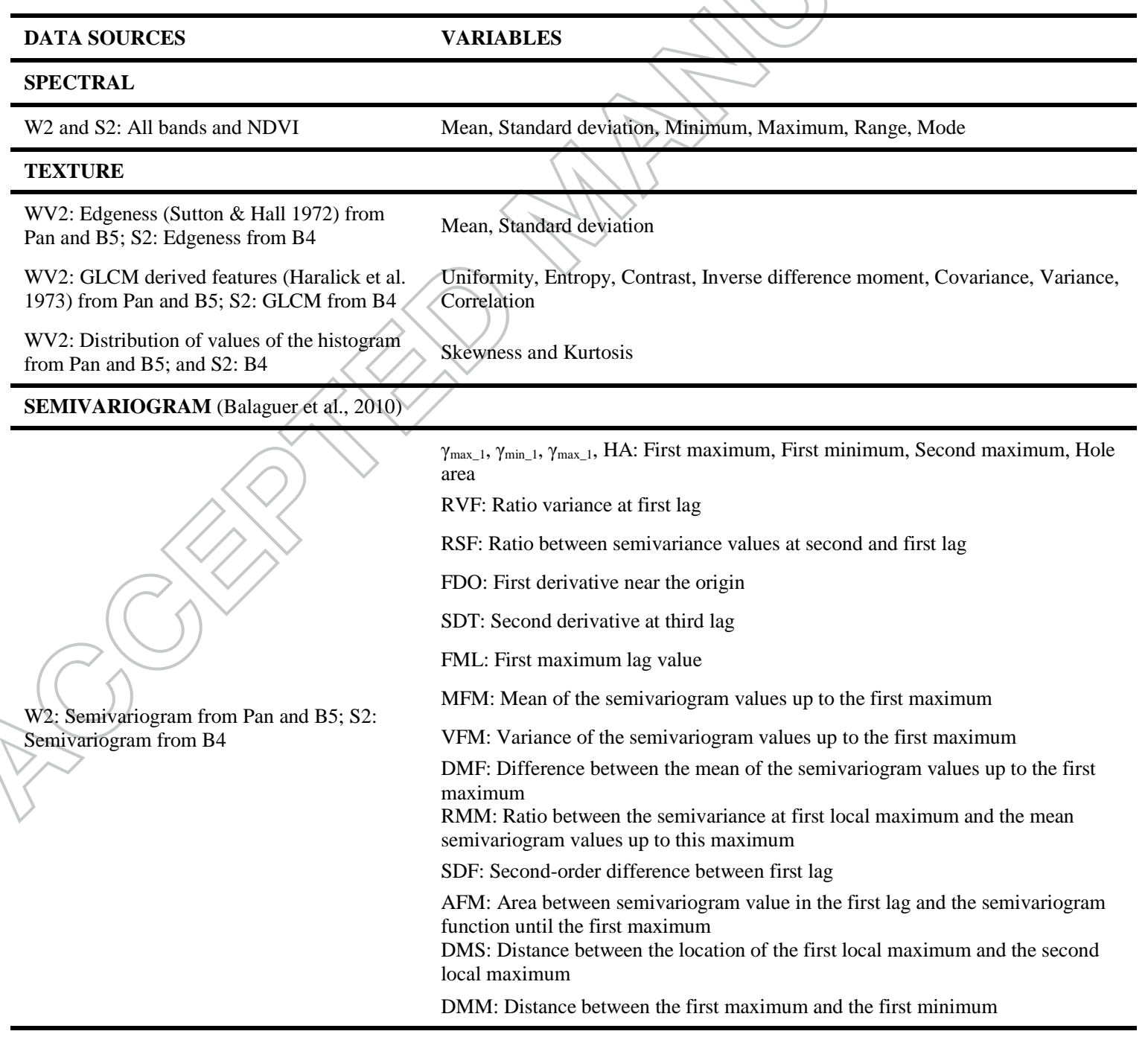




\begin{tabular}{ll}
\hline Objects from segmentation & Compactness, Shape Index, Fractal dimension, Area, Perimeter of the object \\
\hline HEIGHT DISTRIBUTION FEATURES (LiDAR) & Number of returns \\
\hline \multirow{2}{*}{ Point cloud number } & Number of n-order returns \\
& Minimum, Maximum, Mean, Mode, Standard deviation, Variance, Coefficient of \\
& variation, Interquartile distance, Skewness, Kurtosis, Average absolute deviation \\
& Average absolute deviation, L-moments \\
Point cloud elevation and intensity & Coefficient of variation, Skewness and Kurtosis of L-moments \\
& Percentiles (1, 5, 10, 20, 25, 30, 40, 50, 60, 70, 75, 80, 90, 95, 99) \\
Median of the absolute deviations from the overall median & Median of the absolute deviations from the overall mode \\
Canopy relief ratio & Elevation quadratic mean \\
Elevation cubic mean
\end{tabular}

Table 2. Final variables selected for object classification using different data set combinations: WorldView2 (WV2), Sentinel2 (S2), LiDAR (L).

\begin{tabular}{ll}
\hline DATA SET & VARIABLES \\
\hline \multirow{4}{*}{ W2+S2+L } & Mean B8 W2 (Near-IR2) \\
& Maximum NDVI W2 \\
& Elevation Percentile 90 LiDAR \\
& Elevation Quadratic Mean LiDAR \\
& Intensity Kurtosis LiDAR \\
\hline \multirow{3}{*}{ W2+L } & Maximum NDVI W2 \\
& Elevation Percentile 90 LiDAR \\
& Elevation Quadratic Mean LiDAR \\
& Intensity Kurtosis LiDAR \\
\hline S2+L & Mean B2 S2 (Blue) \\
& Elevation Percentile 90 LiDAR \\
& Elevation Quadratic Mean LiDAR \\
& Intensity Kurtosis LiDAR \\
& Intensity L-moment Kurtosis LiDAR \\
\hline & Elevation Percentile 90 LiDAR \\
& Elevation Quadratic Mean LiDAR \\
Intensity Skewness LiDAR & Intensity Kurtosis LiDAR \\
\hline
\end{tabular}


Table 3. Overall comparative results of the four classification methods tested for fuel type discrimination. Results are expressed both, weighted by the area of the objects and only considering the number of objects.

\begin{tabular}{ccccc} 
& \multicolumn{2}{c}{ Overall Accuracy } & \multicolumn{2}{c}{ Kappa Index } \\
\cline { 2 - 5 } & Weighted & No. & Weighted & No. \\
& (Area) & Objects & (Area) & Objects \\
\hline C4.5 & $90.75 \%$ & $86.76 \%$ & 0.863 & 0.764 \\
Random Forest & $90.42 \%$ & $89.30 \%$ & 0.858 & 0.816 \\
kNN (k=5) & $88.00 \%$ & $88.17 \%$ & 0.823 & 0.792 \\
SVM & $86.48 \%$ & $78.31 \%$ & 0.797 & 0.572 \\
\hline
\end{tabular}


Table 4. Overall results for fuel type classification using different dataset combinations: WorldView2 (WV2), Sentinel2 (S2), LiDAR (L). Results are expressed both, weighted by the area of the objects, and considering the number of objects.

\begin{tabular}{ccccc}
\cline { 2 - 5 } & \multicolumn{2}{c}{ Overall Accuracy } & \multicolumn{2}{c}{ Kappa Index } \\
\cline { 2 - 5 } & Weighted & No. & Weighted & No. \\
& (Area) & Objects & (Area) & Objects \\
\hline WV2+S2+L & $90.75 \%$ & $86.76 \%$ & 0.763 & 0.764 \\
WV2+L & $90.95 \%$ & $86.44 \%$ & 0.865 & 0.779 \\
S2+L & $90.15 \%$ & $84.51 \%$ & 0.855 & 0.733 \\
$\mathbf{L}$ & $88.23 \%$ & $82.20 \%$ & 0.824 & 0.685 \\
\hline
\end{tabular}


Figure 1. WorldView-2 false colour infrared image (RGB:753) of Sierra de Espadán, Castellón (Spain). Green polygons represent the samples selected for classification.

Figure 2. Examples of four generic fuel strata to be characterized for classification: a) forest; b) mixed forest; c) shrub; d) young forest.

Figure 3. Overall flow chart of the classification process.

Figure 4. Detail of objects generated after segmentation overlying the nDSM (above). Examples of five segments from different classes (from left to right: forest, mixed forest, shrub, young forest, and grassland) represented on nDSM (center) and WV2 image (below).

Figure 5. Producer's accuracies obtained in the comparative analysis using variables coming from different data set groups to classify five generic fuel types.

Figure 6. User's accuracies obtained in the comparative analysis using variables coming from different data set groups to classify five generic fuel types.

Figure 7. Final classification of generic fuel types of the study area in Natural Park Sierra de Espadán, using C4.5 decision tree algorithm and S2, WV2 and LiDAR features. 


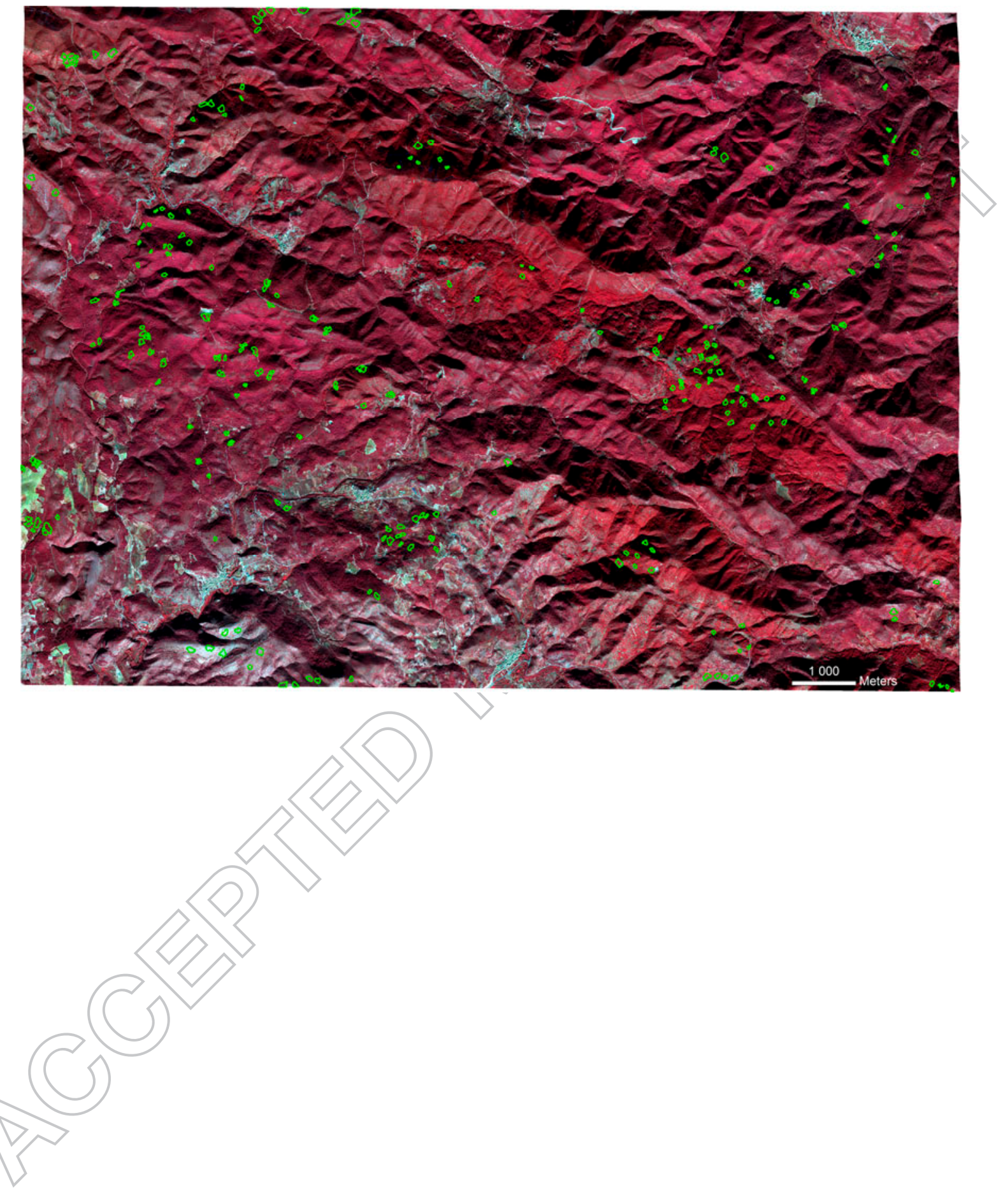



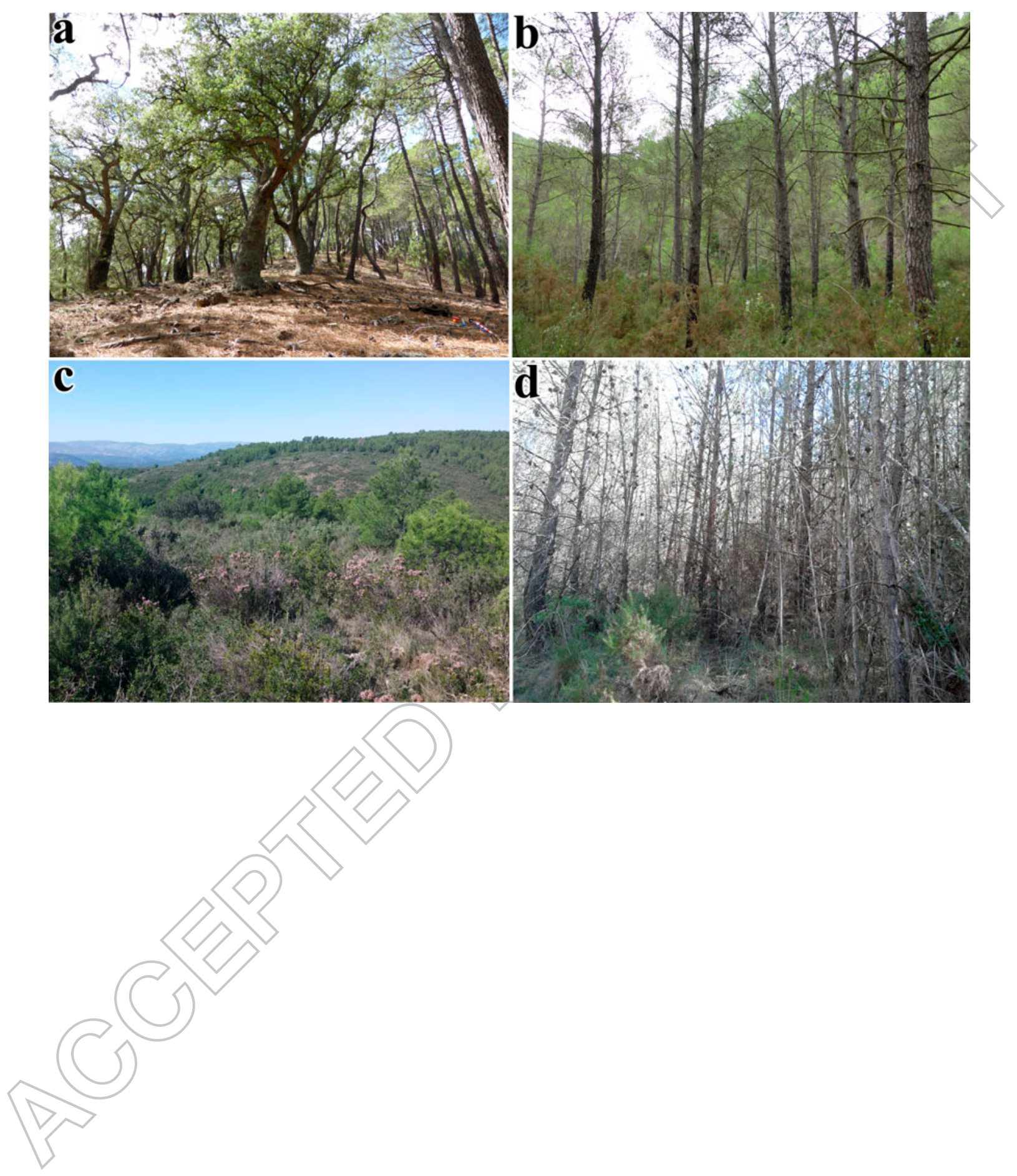


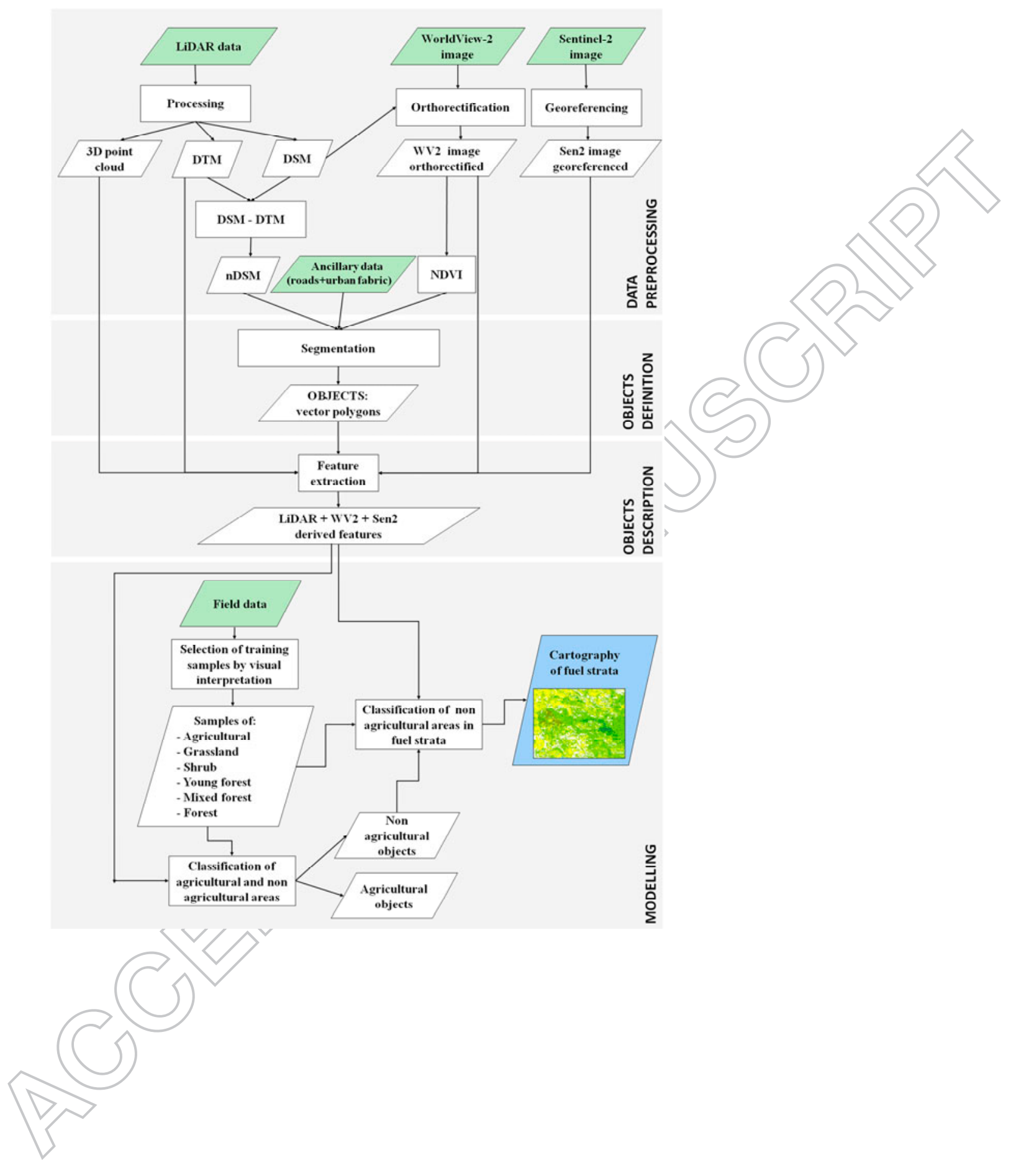




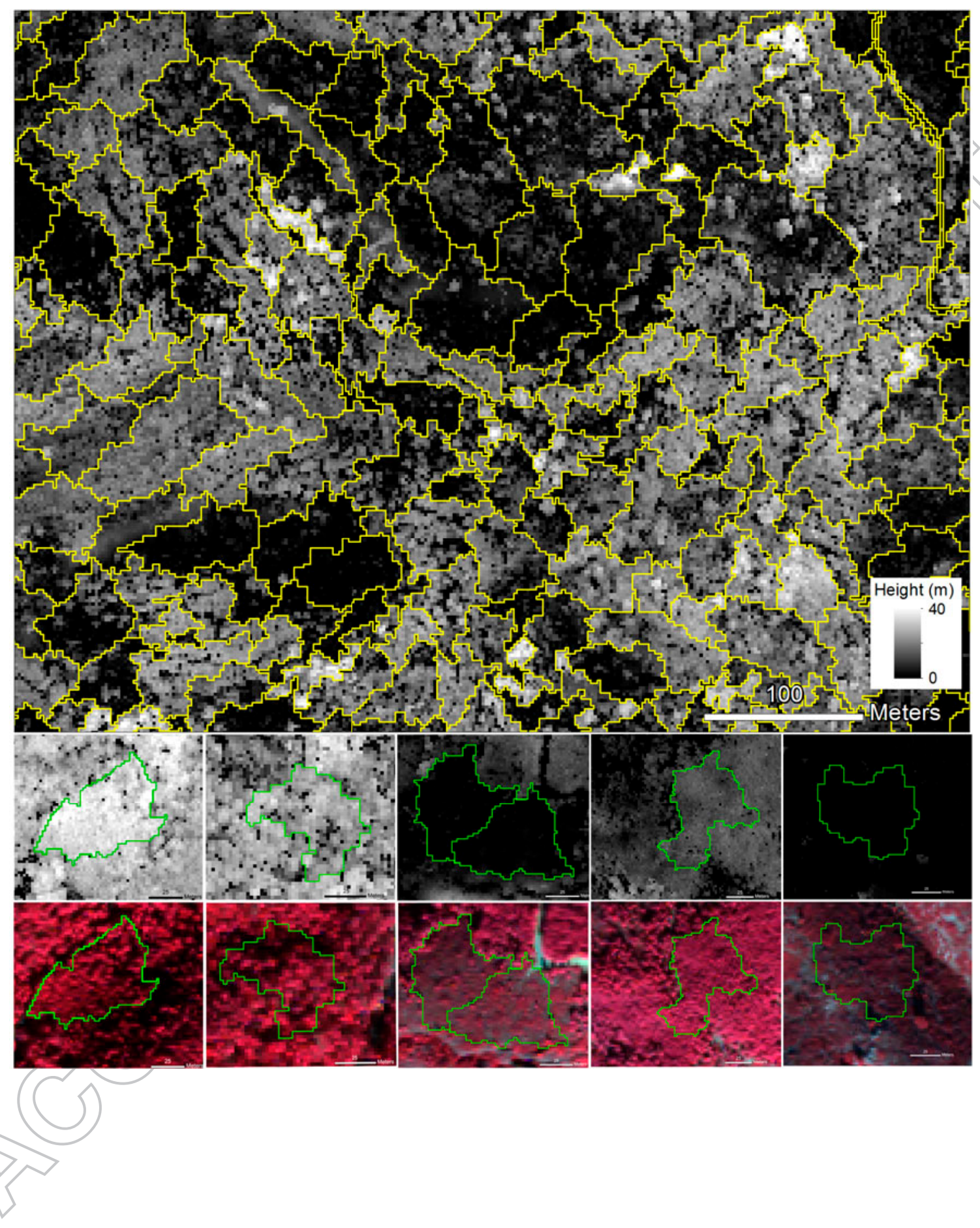


Producer's accuracy

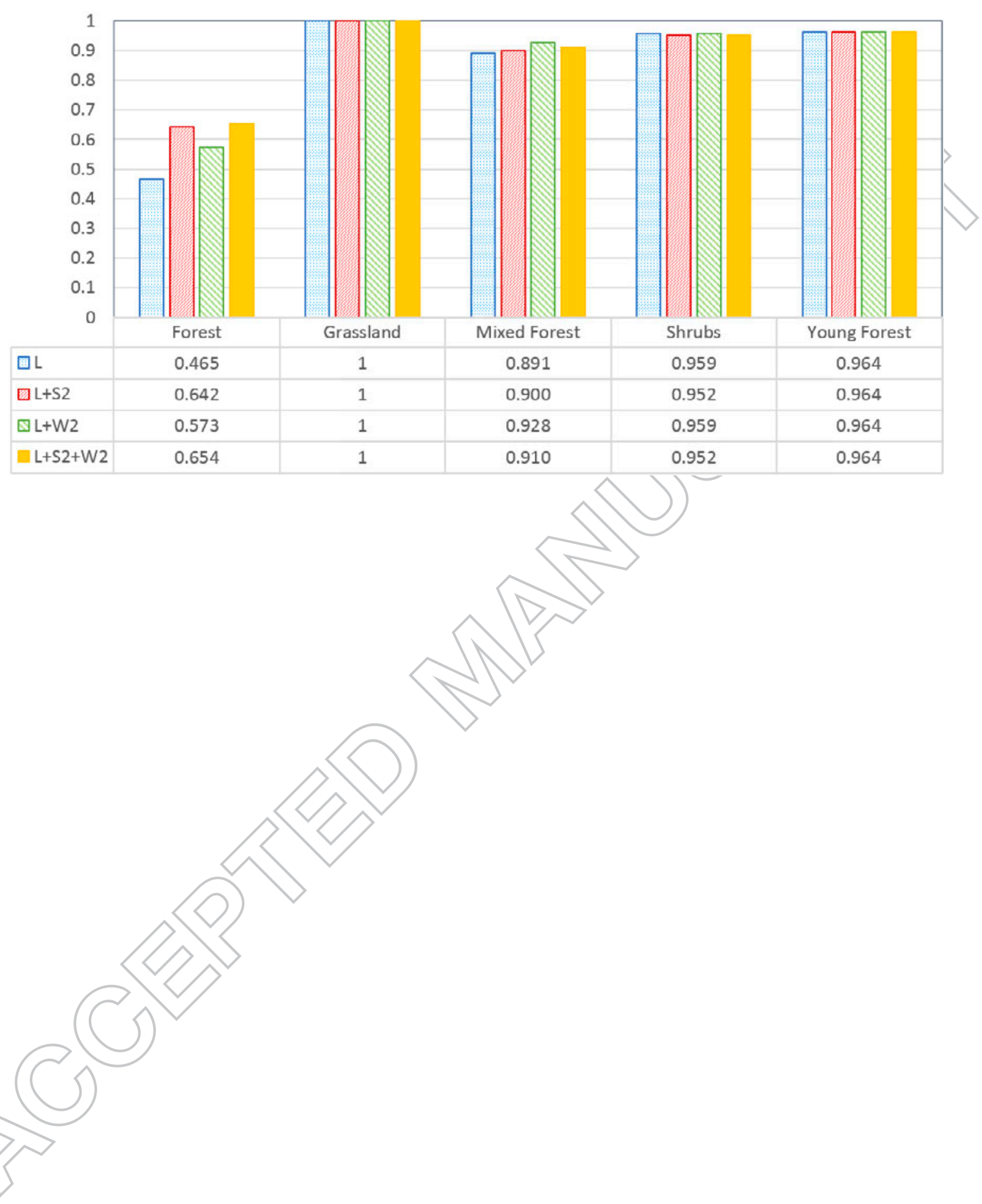




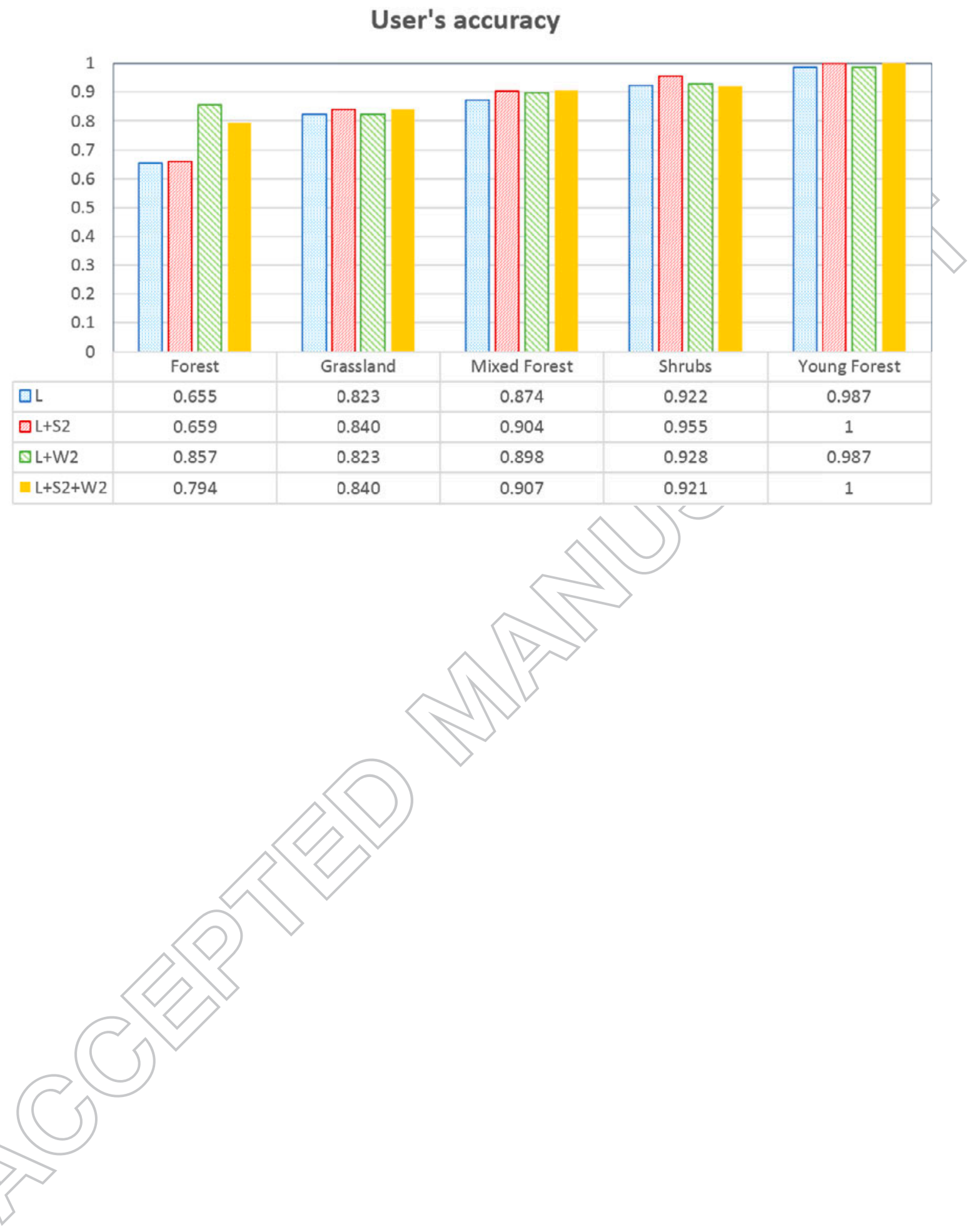




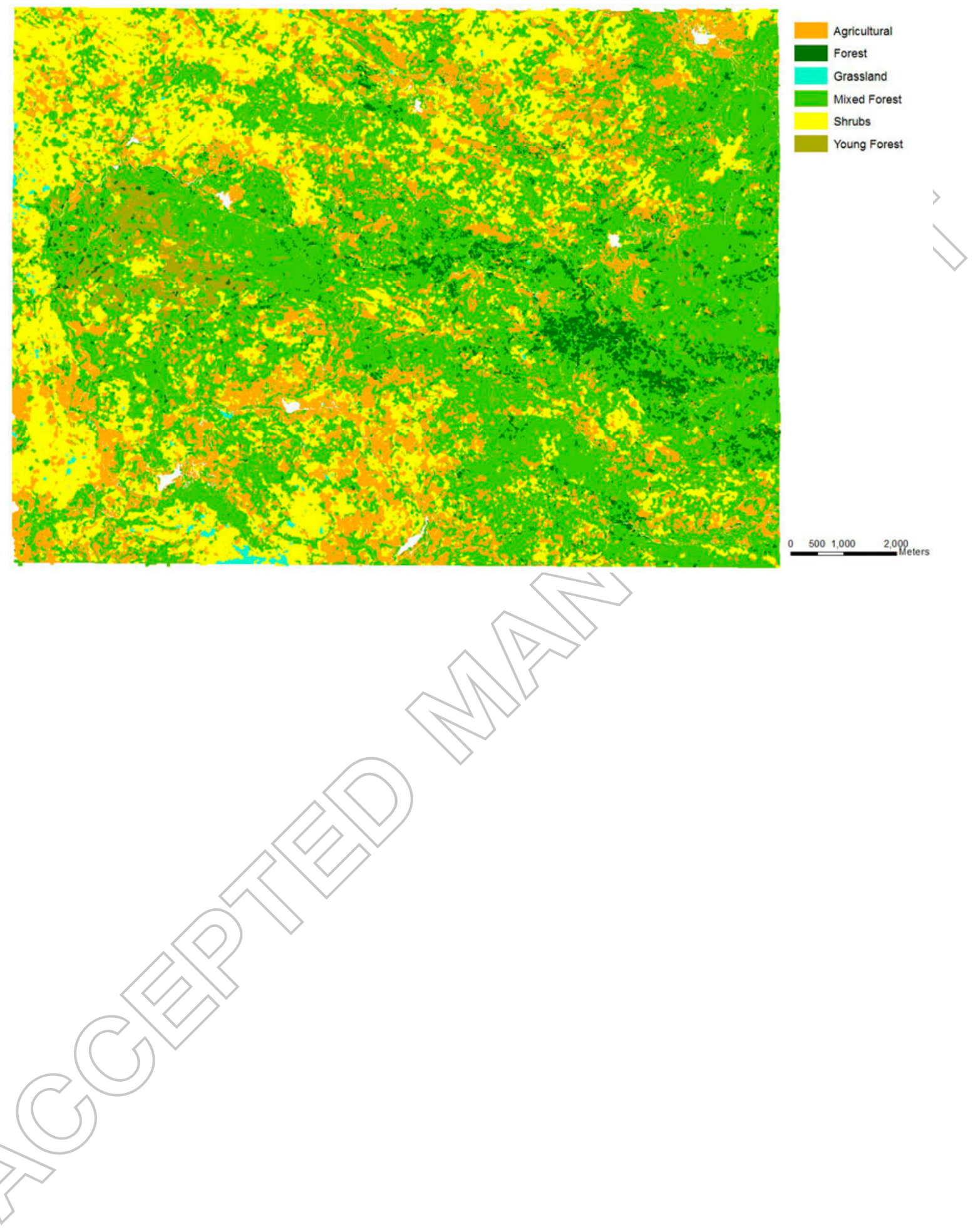

